\title{
Effects of composition of the micro porous layer and the substrate on performance in the electrochemical reduction of $\mathrm{CO}_{2}$ to $\mathrm{CO}$
}

\author{
Byoungsu Kim ${ }^{\mathrm{a}, \mathrm{b}}$, Febrian Hillman ${ }^{\mathrm{a}}$, Miho Ariyoshi ${ }^{\mathrm{b}}$, Shigenori Fujikawa ${ }^{\mathrm{b}, \mathrm{c}}$ and Paul J.A. \\ Kenis ${ }^{a, b, *}$ \\ ${ }^{a}$ Department of Chemical \& Biomolecular Engineering, University of Illinois at \\ Urbana-Champaign, \\ 600 South Mathews Avenue, Urbana, IL 61801, USA. \\ ${ }^{b}$ International Institute for Carbon Neutral Energy Research (WPI-I2CNER), Kyushu University, \\ Fukuoka, Japan. \\ ${ }^{c}$ Center for Molecular System (CMS), Kyushu University, Fukuoka, Japan. \\ * Prof. Paul J.A. Kenis, Corresponding-Author \\ Department of Chemical \& Biomolecular Engineering, \\ University of Illinois at Urbana-Champaign \\ 600 South Mathews Avenue, Urbana, IL 61801, USA \\ E-mail: kenis@illinois.edu
}




\begin{abstract}
With the development of better catalysts, mass transport limitations are becoming a challenge to high throughput electrochemical reduction of $\mathrm{CO}_{2}$ to $\mathrm{CO}$. In contrast to optimization of electrodes for fuel cells, optimization of gas diffusion electrodes (GDE) - consisting of a carbon fiber substrate (CFS), a micro porous layer (MPL), and a catalyst layer (CL) - for $\mathrm{CO}_{2}$ reduction has not received a lot of attention. Here, we studied the effect of the MPL and CFS composition on cathode performance in electroreduction of $\mathrm{CO}_{2}$ to $\mathrm{CO}$. In a flow reactor, optimized GDEs exhibited a higher partial current density for CO production than Sigracet 35BC, a commercially available GDE. By performing electrochemical impedance spectroscopy in a $\mathrm{CO}_{2}$ flow reactor we determined that a loading of $20 \mathrm{wt} \%$ PTFE in the MPL resulted in the best performance. We also investigated the influence of the thickness and wet proof level of CFS with two different feeds, $100 \% \mathrm{CO}_{2}$ and the mixture of $50 \% \mathrm{CO}_{2}$ and $\mathrm{N}_{2}$, determining that thinner and lower wet proofing of the CFS yields better cathode performance than when using a thicker and higher wet proof level of CFS.
\end{abstract}

Keywords: carbon dioxide; electrochemical reduction; gas diffusion electrode; microporous layer; carbon fiber substrate; optimization 


\section{Introduction}

Over the past several decades the atmospheric carbon dioxide $\left(\mathrm{CO}_{2}\right)$ concentration has risen to levels that are now being associated with climate change as well as the abnormal weather patterns [1]. To curb this $\mathrm{CO}_{2}$ rise and ultimately to lower the $\mathrm{CO}_{2}$ levels in the atmosphere, multiple strategies will have to be implemented, including carbon capture and sequestration, improvement of fuel efficiency in the transportation sector, improvement of energy efficiency in buildings, and of course the increased utilization of renewable energy sources, such as solar and wind, which do not produce $\mathrm{CO}_{2}[2]$. However, the intermittent nature of renewable sources necessitates large-scale energy storage or on-demand utilization to exploit energy produced by these renewable sources to maximum, especially for times when the produced renewable energy exceeds demand of the grid. Electrochemical reduction of $\mathrm{CO}_{2}$ into value-added products such as carbon monoxide $(\mathrm{CO})$, formic acid, ethylene and ethanol may provide an additional option to not only reduce $\mathrm{CO}_{2}$ emissions but also utilize excess, otherwise wasted energy from intermittent renewable sources [3-5]. Furthermore, utilization of $\mathrm{CO}_{2}$ as a feedstock for chemical production may reduce global dependency on fossil fuel resources [6, 7].

Significant work is ongoing to improve the catalysts needed for electrochemical reduction of $\mathrm{CO}_{2}$ to different products [8-11]. With better catalysts becoming available, mass transport limitations to and from the electrode surface need to be overcome for electrochemical reduction 
of $\mathrm{CO}_{2}$ to become economically viable. Several factors, including operation under elevated pressure, the use of different gas diffusion electrodes (GDEs), and the use of non-aqueous electrolytes, have been studied to improve diffusive mass transport of the reactants and products to and from the electrodes, and how this effects performance [5].

GDEs have been studied previously for a range of electrochemical applications including fuel cells but have not been optimized explicitly for the electrochemical reduction of $\mathrm{CO}_{2}$ [12-27]. A GDE consists of a carbon fiber substrate (CFS), a micro porous layer (MPL), and a catalyst layer (CL) $[15,26]$. In detail, an MPL, typically is composed of carbon powder and poly-tetrafluoroethylene (PTFE), is known to reduce the contact resistance between the CL and the CFS by forming a flat and strong interfacial layer $[26,27]$. The MPL is also key in maintaining separation between the liquid and gas phase, which is achieved through high surface tension of the liquid-gas-solid interface within its pores $[19,26]$. The extent of this surface tension can be varied by changing the wettability of the MPL [14-18].

In our prior and ongoing work, we use an electrochemical flow reactor, in which a liquid electrolyte flows between two GDEs (a cathode for $\mathrm{CO}_{2}$ reduction and an anode for $\mathrm{O}_{2}$ evolution), while a gaseous $\mathrm{CO}_{2}$ feed flows on another side of cathode GDE, and the anode GDE is exposed to the ambient [28-33]. In addition to control over diffusion-based mass transport of reactants and products close to and within the GDE, control over the liquid electrolyte stream 
and the gaseous $\mathrm{CO}_{2}$ feed is important to maintain pressure balance across the GDEs in order to achieve optimum performance in the electrochemical reduction of $\mathrm{CO}_{2}$ in such an electrochemical flow reactor.

Previously, GDEs have been studied with the goal to improve performance in proton exchange membrane fuel cells (PEMFCs). Many researchers surmised that the main two factors leading to better performance in PEMFCs were better mass transport and higher electrical conductivity $[14,17-19,26]$. To improve these factors, some researchers have optimized the MPL composition, a specific ratio of the amounts of carbon powder and PTFE [14, 15, 18, 19]. Other work studied that the effect of thickness and the level of wet proofing of the CFS on electrode flooding and overall cell performance in PEMFCs [17-19, 23-25]. In all this prior work, the GDEs were optimized for fuel cells, using hydrogen as the fuel. GDEs used for the electrochemical reduction of $\mathrm{CO}_{2}$ will have to be optimized to meet the needs of this chemical conversion. In prior work, we developed an automated air-brush-based catalyst layer deposition method to achieve a thin and uniform catalyst layer, leading to increased current density and improved product selectivity in $\mathrm{CO}_{2}$ reduction [28]. Other work shows that addition of PTFE into the catalyst layer enhances $\mathrm{CO}_{2}$ diffusion and in turn improves cathode performance for the reduction of $\mathrm{CO}_{2}$ to formic acid [34]. Further work is needed, however, to optimize GDEs particularly to facilitate transport of $\mathrm{CO}_{2}$ and the products formed, by studying 
the effects of CFS and MPL composition.

Here we explore the effect of MPL and CFS composition on cathode performance for the electrochemical reduction of $\mathrm{CO}_{2}$ to $\mathrm{CO}$. Specifically, we tune the hydrophobicity of the MPLs (by varying the PTFE content) and we study different levels of wet proofing of CFSs of different thickness to obtain better cathode performance. These different GDEs, including a commercially available GDE, are tested in electrochemical flow reactor with respect their ability for electroreduction of $\mathrm{CO}_{2}$ to $\mathrm{CO}$. Electrochemical impedance spectroscopy (EIS) is used to relate the observed performance with GDE composition. Furthermore, to observe the improvement of mass transport with the optimization of GDEs, performance using two different feeds $\left(100 \% \mathrm{CO}_{2}\right.$ and the mixture of $50 \% \mathrm{CO}_{2}$ and $\left.50 \% \mathrm{~N}_{2}\right)$ was compared.

\section{Experimental}

\subsection{Preparation of GDEs}

Figure 1 shows the sequence of steps used to fabricate the GDEs used in this study. To prepare carbon ink for the MPL, a mixture of carbon powder (carbon black Vulcan XC-72R, Fuel cell store), $100 \mu \mathrm{L}$ of Milipore water (18.2 M 2 ), $200 \mu \mathrm{L}$ of isopropyl alcohol (Avantor), and different amounts of $60 \mathrm{wt} \%$ PTFE dispersion in water (Sigma Aldrich) was sonicated for 30 minutes. The resulting carbon pastes were cast onto different Toray papers (Fuel Cell Earth), 
followed by drying for 3 hours. The sample was sintered under $\mathrm{N}_{2}$ at $350{ }^{\circ} \mathrm{C}$ for 30 minutes to distribute PTFE throughout the MPL. To determine the optimum amount of PTFE in the MPL, PTFE amounts were varied between 4.5 and $50 \mathrm{wt} \%$ of the MPL. Furthermore, for the study of CFSs, the thickness and wet proofing of Toray paper were varied between 170 and $380 \mu \mathrm{m}$ and between 5 and $50 \%$, respectively. For comparison, commercially available Sigracet 35BC gas diffusion layers (GDLs, Ion Power) comprised of 5 wt $\%$ PTFE-treated carbon paper and a teflonized microporous layer, were used. To prepare the catalyst ink for the cathodes, $200 \mu \mathrm{L}$ of Milipore water $(18.2 \mathrm{M} \Omega), 4.0 \mathrm{mg}$ of $\mathrm{Ag}$ catalyst (unsupported $\mathrm{Ag}$ nanoparticles, $<100 \mathrm{~nm}$ particle size, $99.5 \%$ trace metals basis, Sigma-Aldrich), $5.2 \mu \mathrm{L}$ of Nafion solution (5 wt $\%$, Fuel Cell Earth), and $200 \mu \mathrm{L}$ of isopropyl alcohol (Avantor) were mixed. Then, to cover electrodes with this Ag cathode catalyst, the catalyst inks were applied onto the GDLs, so onto the MPL deposited on Toray paper (See above), or onto the teflonized carbon side of Sigracet 35 BC, using an automated air-brushing deposition setup [28]. The total geometric area of the cathode GDE covered with catalyst is $2 \mathrm{~cm}^{2}$. The catalyst ink for the anodes was comprised of $4.20 \mathrm{mg}$ $\mathrm{IrO}_{2}$ black (Alfa Aesar), 13.0 $\mu \mathrm{L}$ Nafion solution, as well as $200 \mu \mathrm{L}$ of isopropyl alcohol, and $200 \mu \mathrm{L}$ Millipore water (18.2 M $)$ as the carrier solvents [29]. This catalyst ink is painted on a Sigracet 35BC over a geometric area of $1.0 \times 2.5 \mathrm{~cm}^{2}$ using a paintbrush. To achieve uniform mixing, all the catalyst inks were sonicated for 15 minutes prior to paint. The weight of the 
GDEs was measured before/after deposition of catalyst to confirm the actual catalyst loading: 0.8 $\mathrm{mg} \mathrm{Ag} / \mathrm{cm}^{2}$ and $2.0 \mathrm{mg} \mathrm{IrO}_{2} / \mathrm{cm}^{2}$, respectively for the cathodes and anodes.

\subsection{Electrochemical flow reactor assembly and its use for electrode testing}

An electrochemical flow reactor used in this study as reported previously was used to perform the electrochemical reduction of $\mathrm{CO}_{2}$ to $\mathrm{CO}$ [28-30]. In short, the flow reactor in which two catalyst-coated electrodes (an anode and a cathode) are separated by a flowing liquid electrolyte was used. On the cathode side, a gas chamber supplied $\mathrm{CO}_{2}$ while the anode was open to the atmosphere for $\mathrm{O}_{2}$ to escape. With the use of $1 \mathrm{M}$ potassium hydroxide $(\mathrm{KOH}$, Fisher Scientific, certified ACS pellets) in water, the $\mathrm{CO}_{2}$ electroreduction reaction takes place on the cathode whereas the oxygen evolution reaction takes place on the anode. A syringe pump (PHD 2000, Harvard Apparatus) supplied the electrolyte, $1 \mathrm{M} \mathrm{KOH}$ in water, between the anode and cathode GDEs at a flow rate of $0.5 \mathrm{ml} \mathrm{min}^{-1}$. The electrochemical flow reactor was operated using a potentiostat (Autolab PGSTAT-30, EcoChemie) under ambient pressure and temperature. For each applied potential, the cell was allowed to reach steady state for 200 s, at which point the current had stabilized. The current at a given applied potential was obtained by averaging the current over 180s. The individual electrode potentials were recorded using multimeters (AMPROBE 15XP-B) connected to each electrode and a reference electrode (Ag/AgCl, RE-5B, BASi) placed in the electrolyte exit stream. The gaseous product stream 
was characterized using a gas chromatograph (Trace GC, ThermoFisher Scientific) equipped with a Carboxen 1000 column (Supelco) and a thermal conductivity detector. The only cathode products detected by $\mathrm{GC}$ were $\mathrm{CO}$ and $\mathrm{H}_{2}$ when using $\mathrm{Ag}$ as the catalyst. A mass flow controller (MASS_FLO, MKS instrument) was used to set the $\mathrm{CO}_{2}$ (S.J. Smith Welding Supply) and $\mathrm{N}_{2}$ (S.J. Smith Welding Supply) at $7 \mathrm{sccm}$ of total flow rate. A freshly prepared cathode was used for every experiment. Each anode was used for 3 to 5 experiments. No deactivation of electrode activity was observed during each experiment. The $\mathrm{pH}$ of the electrolyte was measured using a calibrated $\mathrm{pH}$ meter (Thermo Orion, 9106BNWP). Faradaic efficiencies and current densities are calculated by using equations reported previously [4].

\subsection{Physical characterization of electrodes}

The structure of the GDEs was characterized using SEM and Micro-CT. Cross-sectional images of samples were obtained using SEM (Philips XL30 ESEM-FEG) using an acceleration voltage of $10.0 \mathrm{kV}$ and a spot size of $3.0 \mathrm{~nm}$, resulting in a magnification of 1,300 . Images of the structural features of the top surface of the GDEs over an area of several square millimeters was obtained using Micro-CT (Micro-XCT 400, Xradia) using an X-ray source at 40kV and a current of $200 \mu \mathrm{A}$.

\subsection{Electrochemical impedance spectroscopy}

Electrochemical impedance spectroscopy (EIS) was carried out on the electrochemical flow 
reactor using the frequency response module of the potentiostat (Autolab PGSTAT-30, EcoChemie) under ambient pressure and temperature. The spectra were recorded at a cell potential of $-2.00 \mathrm{~V}$ with an ac-amplitude of $10 \mathrm{mV}$ over the frequency range from $0.1 \mathrm{~Hz}$ to 10 kHz. The high frequency intercepts on the $\mathrm{x}$-axis of the Nyquist plot represent the internal resistance of the cell $\left(\mathrm{R}_{\text {cell }}\right)$ which includes the cell contact resistance and the electrolyte solution resistance. The diameter of the semicircular feature represents the charge transfer resistance $\left(\mathrm{R}_{\mathrm{ct}}\right)$ of the cell.

\subsection{Gas permeation experiment}

Prepared GDE samples were placed on a stainless steel mesh support and this assembly was mounted on a homemade cylindrical holder, with an outer and inner diameter of $12 \mathrm{~mm}$ and 25 $\mathrm{mm}$, respectively. The area tested for gas permeability equals the area of the inner diameter, $1.13 \mathrm{~cm}^{2}$. Then, another cylindrical sample holder connected with the tube for gas inlet is placed on top. $\mathrm{A} \mathrm{CO}_{2}$ feed gas was introduced from the inlet at a flow rate of $100 \mathrm{sccm}$. The gas pressure just before the membrane is monitored. The flow rate of the permeant gas was determined using a bubble flow meter (Horiba, Co. Ltd., Film flow meter VP-2).

\section{Results and Discussion}

\subsection{Effect of Micro Porous Layer (MPL)}


GDEs based on Toray paper with and without an MPL ( $1 \mathrm{mg} \mathrm{cm}^{-2}$ carbon and $20 \mathrm{wt} \%$ PTFE)

were tested to underline the importance of the MPL (Fig. 2). For both tests, we used an identical catalyst loading of $0.8 \mathrm{mg} \mathrm{cm}^{-2}$ and $1 \mathrm{M} \mathrm{KOH}$ as the electrolyte. The GDE with MPL exhibits better performance than the GDE without MPL (Fig. 2e). Specifically, at -2.05 V vs. $\mathrm{Ag} / \mathrm{AgCl}$, the partial current density for CO for the GDE with MPL was $280 \mathrm{~mA} \mathrm{~cm}{ }^{-2}$, whereas the partial current density for CO for the GDE without MPL was only $28 \mathrm{~mA} \mathrm{~cm}^{-2}$ (about 10 times lower). SEM and Micro-CT show that catalyst is uniformly distributed on the MPL for the GDE with MPL (Fig. 2a and b). In the absence of an MPL, the obtained partial current densities for $\mathrm{CO}$ were below $30 \mathrm{~mA} \mathrm{~cm}$, irrespective of the cathode potentials. This poor performance observed for GDEs that lack an MPL can be explained by several factors, including irregularly distributed $\mathrm{Ag}$ particles on and between the carbon fibers of the CFS (so a poorly defined catalyst layer, CL), and as a result, the presence of exposed carbon fibers, leading to undesired high levels of $\mathrm{H}_{2}$ evolution. Both structural features are apparent from SEM and Micro-CT data (Fig. 2c and d). Also, the absence of an MPL causes saturation of the CFS with electrolyte, often leading to flooding of the CL during testing. Novel methods to deposit CLs directly on the CFS could improve catalyst utilization, but the existence of MPLs is still important to improve the performance of the GDE by being able to better contain the electrolyte. The better performance obtained for GDEs with MPL can be attributed to improved electrolyte 
management (the ability to suppress flooding), as well as increased electronic conductivity of the GDE, and reduced loss of catalyst by ink penetration into the CFSs during deposition $[19,26$, 35]. As expected, the results here indicate that the presence of an MPL in GDEs is key in providing physical support for the $\mathrm{CL}$ and in providing better control over the electrolyte, leading to better performance for reduction of $\mathrm{CO}_{2}$.

\subsection{Effect of PTFE in MPL}

Next we studied the effect of the amount of PTFE in MPLs on the electrochemical reduction of $\mathrm{CO}_{2}$. PTFE is commonly used as a binder, connecting separate carbon particles [36]. A higher PTFE content increases the hydrophobicity of MPLs at the expense of increasing electrical resistance. The carbon loading in the MPLs was kept constant for all MPLs. Other researchers investigated the effects of carbon loading in PEMFC because an MPL needs to be thick enough to remove water produced during the reaction $[18,35,37]$. However, for electrochemical reduction of $\mathrm{CO}_{2}$, the role of MPL may be reduced because the MPL does not need to transport water but needs to be hydrophobic enough to keep the electrolyte confined to the CL side of the MPL. Prior work has shown that thin MPLs provide a short gas diffusion path and thus improve gas diffusion, leading to better performance in PEMFCs [17, 19]. For the same reasons, we also use thin MPLs (in the range of $15 \mu \mathrm{m}$, corresponding to a loading of 
about $1 \mathrm{mg} \mathrm{cm}^{-2}$ carbon) in this study. These MPLs are sufficiently thick to form a complete layer on top of Toray paper while they allow easy diffusional access for the reactants to reach the catalyst sites.

To investigate the effect of the amount of PTFE in the MPLs on cathode performance, GDEs comprised of MPLs with different amounts of PTFE (4.5 to $50 \mathrm{wt} \%$ ) but identical CLs were fabricated and tested in the $\mathrm{CO}_{2}$ flow reactor. In prior work, reported optimized values for the amount of PTFE in MPLs for fuel cells have varied from 10 to $30 \mathrm{wt} \%$, with the specific optimal amount depending on the structure of the cells used as well as their operating conditions $[14,15$, 17]. Fig. 3 a-d shows plots of the partial current density for $\mathrm{CO}$ and $\mathrm{H}_{2}$ versus the cathode potential for GDEs prepared with a constant $\mathrm{Ag}$ loading of $0.8 \mathrm{mg} \mathrm{cm}{ }^{-2}$. For GDEs with 4.5 to $20 \mathrm{wt} \%$ PTFE MPLs, the data indicates that the higher PTFE amount, the higher partial current density for $\mathrm{CO}$ and the lower partial current density for $\mathrm{H}_{2}$, especially at more negative cathode potentials (Fig. 3a and b). The partial current density for $\mathrm{CO}$ reaches a maximum value for GDEs with $20 \mathrm{wt} \%$ PTFE MPLs, and then decreases with a further increase in the amount of PTFE in MPLs (Fig. 3c).

High partial current densities for $\mathrm{H}_{2}$ are observed for GDEs with 4.5 to $10 \mathrm{wt} \%$ PTFE MPLs (Fig. 3b). Insufficient hydrophobicity in the MPLs results in flooding of the electrode, which in turn hampers diffusion of $\mathrm{CO}_{2}$ to the CL. Also, the GDEs with low PTFE amounts in MPL 
exhibit poor durability, evident from areas of exposed CFS being visible after testing; the low PTFE amount in these MPLs was insufficient to retain the carbon particles and CL during operation. These observed trends in the dependence of the partial current density for $\mathrm{CO}$ as a function of the PTFE amount (4.5 to $20 \mathrm{wt} \%$ ) are similar to what has been observed previously in fuel cells $[14,15,22]$.

On the other hand, for GDEs with 30 to $50 \mathrm{wt} \%$ PTFE MPLs, the partial current densities for $\mathrm{CO}$ decreased with a further increase of the amount of PTFE (Fig. 3c). Specifically, at $-2.2 \mathrm{~V}$ vs. $\mathrm{Ag} / \mathrm{AgCl}$, the partial current density for CO for GDE with a $20 \mathrm{wt} \%$ PTFE MPL was $280 \mathrm{~mA}$ $\mathrm{cm}^{-2}$, whereas GDEs with $40 \mathrm{wt} \%$ and $50 \mathrm{wt} \%$ PTFE MPLs reached only 198 and $183 \mathrm{~mA} \mathrm{~cm}^{-2}$, respectively (Fig. 3f). Compared to our prior work [29], the GDE with the $20 \mathrm{wt} \%$ PTFE MPL led to an enhancement in cathode performance of up to $5 \%$ under the same conditions with the same catalysts, despite of a slightly lower Ag loading $\left(0.8\right.$ instead of $\left.1.0 \mathrm{mg} \mathrm{cm}^{-2}\right)$. Also, note that the GDEs with MPL achieve a Faradaic efficiency for CO exceeding 90\%, irrespective of the PTFE amounts present in the MPL.

EIS data (Fig. 3e) suggests that the increased electrical resistance (charge transfer resistance, $\mathrm{R}_{\mathrm{ct}}$ ) may have caused a decrease in performance for GDEs with a PTFE loading exceeding 20 wt\% in MPL. The electrical resistance increases by a factor of 3 as PTFE amounts in MPL change from 20 to $50 \mathrm{wt} \%$ while the cell resistance, $\mathrm{R}_{\text {cell }}$, is approximately the same for all GDEs, 
irrespective of the amount of PTFE in the MPLs. This increase in $R_{c t}$ can be explained by a decrease of conductivity in GDE due to the higher non-conductive material content (PTFE), which is similar to what has been observed in the fuel cell literature [21]. Alternatively, the low cathode performance for GDEs with more than $20 \mathrm{wt} \%$ PTFE in their MPLs may be due to limited diffusion of $\mathrm{CO}_{2}$, as a result of the higher amounts of PTFE reducing the porosity of the GDEs [24]. For example, Lin et al. stated that the pore diameter and corresponding pore volumes of the GDLs may be key to the high performance observed in fuel cells [23].

\subsection{Effect of wet proof level in CFS}

One of the main advantages of the homemade MPLs studied in Section 3.2 is that we could apply the optimal composition of MPL onto a variety of CFSs. The $20 \mathrm{wt} \%$ PTFE MPL, which showed the optimum performance earlier, was applied to the different wet proof level of CFSs $(10-50 \%)$. Table 1 provides details on the GDE samples with the different level of wet proofing of their CFSs. To observe improvement of mass transport with the optimization of GDE, their performance was tested with two different reactant feeds $\left(100 \% \mathrm{CO}_{2}\right.$ and the mixture of $50 \% \mathrm{CO}_{2}$ and $50 \% \mathrm{~N}_{2}$ ). As expected, the partial current density for $\mathrm{CO}$ increases with increasing $\mathrm{CO}_{2}$ partial pressure (Fig. 4). Mass transport limitation was only observed when using the mixture of $50 \% \mathrm{CO}_{2}$ and $50 \% \mathrm{~N}_{2}$ as a feed (Fig. 4b). Fig. 4 also shows that the GDE 
containing a CFS with a wet proof level of $10 \%$ exhibits a higher partial current density for CO than GDEs with CFS with higher wet proof levels (30 and 50\%) regardless of the reactant feed used. Specifically, the GDE with $10 \%$ wet proof level of CFS exhibits $224 \mathrm{~mA} \mathrm{~cm}^{-2}$ of partial current density for CO, whereas the GDEs with 30 and 50\% wet proof level of CFSs show 190 and $158.41 \mathrm{~mA} \mathrm{~cm}^{-2}$ of partial current density for $\mathrm{CO}$, respectively at cathode potential of -2.05 V when using a $100 \% \mathrm{CO}_{2}$ feed (Fig. 4a). A similar trend was found when using the $50-50 \mathrm{CO}_{2}$ and $\mathrm{N}_{2}$ feed (Fig. 4b).

We also determined gas permeability and electrical resistance of some of the GDEs; properties that are known to be important in determining their performance $[14,17,19,26]$. GDEs with a lower level of wet proofing level exhibited higher gas permeability, but the observed difference is not sufficient to explain the difference in cathode performance (Table 2). In contrast, the GDE with $10 \%$ wet proofing exhibited a much lower electrical resistance than the GDEs with 30 and 50\% wet proof levels (Fig. 4c), so the difference in cathode performance can be mainly attributed to this difference in electrical resistance.

Next, to test the durability of the GDEs with different wet proof levels, we investigated the cathode performance during continuous operation in a $\mathrm{CO}_{2}$ flow reactor over 4 hours at a cathode potential of $-1.60 \mathrm{~V}$ vs. $\mathrm{Ag} / \mathrm{AgCl}$. Neither flooding of electrolyte through GDE nor any significant performance drop was observed for the two GDEs tested (wet proofing of 10 and 
50\%) over this 4-hr test (Fig. 5). This data suggests that both electrodes are stable under these operation conditions for multiple hours, but longer experiments would be needed to determine their durability over more extended periods of time. Given that the GDEs with lower levels of wet proofing exhibit better cathode performance, and that there is no difference in stability, these GDEs should be used for electrochemical reduction of $\mathrm{CO}_{2}$.

\subsection{Effect of thickness in CFS}

Next, to try to further improve cathode performance, we tested different GDEs comprised of an MPL loaded with 20 wt $\%$ PTFE and a CFS with a $10 \%$ wet proof level (the optimum compositions determined in the sections above) but with CFSs of different thickness, as specified in Table 1. Fig. 6 shows that the GDE with the thinner CFS (carbon/PTFE/CFS thickness-wet proofing $=1 / 20 \% / 60-10 \%)$ exhibits a higher partial current density for CO than the GDEs with the thicker CFSs (1/20\%/90-10\% and 1/20\%/120-10\%) including the commercially available Sigracet $35 \mathrm{BC}$, regardless of whether a $50 \% \mathrm{CO}_{2}$ or $100 \% \mathrm{CO}_{2}$ reactant feed was used. The enhanced cathode performance is more significant when using the dilute feed (50-50 $\mathrm{CO}_{2}$ and $\mathrm{N}_{2}$ ). The GDE with thinner CFS exhibits a partial current density for $\mathrm{CO}$ of $171.5 \mathrm{~mA} \mathrm{~cm}^{-2}$, whereas the commercial GDE (Sigracet 35BC) exhibits only $125 \mathrm{~mA} \mathrm{~cm}^{-2}$ when applying a cathode potential of $-2.05 \mathrm{~V}$ and using a $50-50 \% \mathrm{CO}_{2}$ and $\mathrm{N}_{2}$ feed (Fig. 6b). Upon reducing the thickness of the CFS reduces from 370 to $190 \mu \mathrm{m}$, the measured gas permeability of these 
GDEs also improves which explains their enhanced cathode performance (Table 2). Specifically, the measured gas permeability of GDEs with homemade MPLs is much higher than that of Sigracet 35BC, explaining the difference in cathode performance. Similarly, use of GDEs with a thinner CFS has been shown to improve fuel cell performance, probably also due to improved gas diffusion $[12,23]$. We also studied a GDE with an even thinner CFS (Toray-30), but this electrode exhibited extensive flooding (electrolyte seeping through the GDE) during testing, indicating that a certain minimum CFS thickness is required for suitable performance in the electrochemical reduction of $\mathrm{CO}_{2}$. In summary, using a GDE with a thin CFS $(\sim 190 \mu \mathrm{m})$ in combination with a CFS with optimized levels of wet proofing (10\% PTFE) and a MPL with optimized levels of hydrophobicity (20\% PTFE) resulted in the best cathode performance for electroreduction of $\mathrm{CO}_{2}$.

\section{Conclusion}

The experiments reported here provide insight regarding the composition and structure of GDEs that leads to the best performance in the electrochemical reduction of $\mathrm{CO}_{2}$ to $\mathrm{CO}$. Specifically, the electrode composition must be carefully controlled to prevent electrolyte flooding and to improve gas permeability as well as conductivity. We determined an optimum level of hydrophobicity of the MPL (20 wt\% PTFE), an optimum level of wet proofing of the CFS (10 wt\% PTFE), and an optimum thickness of the CFS (Toray-60, $190 \mu \mathrm{m}$ ). These GDEs 
lead to partial current densities for $\mathrm{CO}$ production as high as $280 \mathrm{~mA} \mathrm{~cm}$ at a cathode potential

of $-2.2 \mathrm{~V}$, and exhibit no decay in performance during continuous operation for 4 hours. Note that these GDEs also outperform commercially available GDEs such as Sigracet 35BC.

Understanding and being able to quantify the effects of different composition and structure of MPLs and CFSs benefits the design of electrodes for electrochemical $\mathrm{CO}_{2}$ reduction, or other electrocatalytic process involving gaseous reactant feeds. Looking forward, further improvement of GDE performance may be achieved by investigating factors such as different carbon materials for the MPL and the effects of post fabrication treatments like hot pressing [38]. Similarly, improvement of the composition and structure of the anode holds promise for further improvement of electrochemical $\mathrm{CO}_{2}$ reduction in electrolyzers. In addition, extensive durability tests of electrodes can bring the electroreduction of $\mathrm{CO}_{2}$ process a step forward [39].

\section{Acknowledgments}

We gratefully acknowledge financial support from the Department of Energy through an STTR grant to Dioxide Materials and UIUC (DE-SC0004453) and the International Institute of Carbon Neutral Energy Research (I2CNER), sponsored by the Research Center Initiative (WPI), MEXT, Japan. BK acknowledges support from a Dow Chemical Company graduate fellowship. 


\section{References}

[1] P. Falkowski, R.J. Scholes, E. Boyle, J. Canadell, D. Canfield, J. Elser, N. Gruber, K. Hibbard, P. Hogberg, S. Linder, F.T. Mackenzie, B. Moore, T. Pedersen, Y. Rosenthal, S. Seitzinger, V. Smetacek, W. Steffen, Science 290 (2000) 291-296.

[2] S. Pacala, R. Socolow, Science 305 (2004) 968-972.

[3] D.T. Whipple, P.J.A. Kenis, The Journal of Physical Chemistry Letters 1 (2010) 3451-3458.

[4] H.-R.M. Jhong, S. Ma, P.J.A. Kenis, Current Opinion in Chemical Engineering 2 (2013) 191-199.

[5] Y. Hori, Electrochemical CO2 Reduction on Metal Electrodes, in: C.G. Vayenas, R.E. White, M.E. GamboaAldeco (Eds.) Modern Aspects of Electrochemistry, No 42, Springer, New York, 2008, pp. 89-189.

[6] G. Centi, S. Perathoner, Catalysis Today 148 (2009) 191-205.

[7] A.M. Appel, J.E. Bercaw, A.B. Bocarsly, H. Dobbek, D.L. DuBois, M. Dupuis, J.G. Ferry, E. Fujita, R. Hille, P.J.A. Kenis, C.A. Kerfeld, R.H. Morris, C.H.F. Peden, A.R. Portis, S.W.

Ragsdale, T.B. Rauchfuss, J.N.H. Reek, L.C. Seefeldt, R.K. Thauer, G.L. Waldrop, Chemical Reviews 113 (2013) 6621-6658.

[8] C.W. Li, M.W. Kanan, Journal of the American Chemical Society 134 (2012) 7231-7234.

[9] Q. Lu, J. Rosen, Y. Zhou, G.S. Hutchings, Y.C. Kimmel, J.G. Chen, F. Jiao, Nat Commun 5 (2014).

[10] M. Asadi, B. Kumar, A. Behranginia, B.A. Rosen, A. Baskin, N. Repnin, D. Pisasale, P. Phillips, W. Zhu, R. Haasch, R.F. Klie, P. Král, J. Abiade, A. Salehi-Khojin, Nat Commun 5 (2014).

[11] C.E. Tornow, M.R. Thorson, S. Ma, A.A. Gewirth, P.J.A. Kenis, Journal of the American Chemical Society 134 (2012) 19520-19523.

[12] V.A. Paganin, E.A. Ticianelli, E.R. Gonzalez, J. Appl. Electrochem. 26 (1996) 297-304.

[13] E. Passalacqua, F. Lufrano, G. Squadrito, A. Patti, L. Giorgi, Electrochim. Acta 43 (1998) 3665-3673.

[14] F. Lufrano, E. Passalacqua, G. Squadrito, A. Patti, L. Giorgi, J. Appl. Electrochem. 29 (1999) 445-448.

[15] L. Giorgi, E. Antolini, A. Pozio, E. Passalacqua, Electrochim. Acta 43 (1998) 3675-3680.

[16] M. Han, S.H. Chan, S.P. Jiang, J. Power Sources 159 (2006) 1005-1014.

[17] W.-M. Yan, C.-Y. Hsueh, C.-Y. Soong, F. Chen, C.-H. Cheng, S.-C. Mei, Int. J. Hydrogen Energy 32 (2007) 4452-4458.

[18] G.Y. Lin, T. Van Nguyen, J. Electrochem. Soc. 152 (2005) A1942-A1948.

[19] G.-G. Park, Y.-J. Sohn, T.-H. Yang, Y.-G. Yoon, W.-Y. Lee, C.-S. Kim, J. Power Sources 131 (2004) 182-187. 
[20] M.S. Ismail, T. Damjanovic, D.B. Ingham, L. Ma, M. Pourkashanian, J. Power Sources 195 (2010) 6619-6628.

[21] E. Antolini, R.R. Passos, E.A. Ticianelli, J. Appl. Electrochem. 32 (2002) 383-388.

[22] A. Li, M. Han, S.H. Chan, N.-t. Nguyen, Electrochim. Acta 55 (2010) 2706-2711.

[23] J.F. Lin, J. Wertz, R. Ahmad, M. Thommes, A.M. Kannan, Electrochim. Acta 55 (2010) 2746-2751.

[24] M. Prasanna, H.Y. Ha, E.A. Cho, S.A. Hong, I.H. Oh, J. Power Sources 131 (2004) 147-154.

[25] J.D. Fairweather, P. Cheung, D.T. Schwartz, J. Power Sources 195 (2010) 787-793.

[26] A.Z. Weber, J. Newman, J. Electrochem. Soc. 152 (2005) A677-A688.

[27] M.J. Martínez-Rodríguez, T. Cui, S. Shimpalee, S. Seraphin, B. Duong, J.W. Van Zee, J. Power Sources 207 (2012) 91-100.

[28] H.-R.M. Jhong, F.R. Brushett, P.J.A. Kenis, Adv. Energy Mater. 3 (2013) 589-599.

[29] S. Ma, R. Luo, S. Moniri, Y.C. Lan, P.J.A. Kenis, J. Electrochem. Soc. 161 (2014) F1124-F1131.

[30] B. Kim, S. Ma, H.-R. Molly Jhong, P.J.A. Kenis, Electrochim. Acta 166 (2015) 271-276.

[31] E.J. Dufek, T.E. Lister, S.G. Stone, M.E. McIlwain, J. Electrochem. Soc. 159 (2012) F514-F517.

[32] A. Salehi-Khojin, H.-R.M. Jhong, B.A. Rosen, W. Zhu, S. Ma, P.J.A. Kenis, R.I. Masel, The Journal of Physical Chemistry C 117 (2013) 1627-1632.

[33] J. Wu, F.G. Risalvato, P.P. Sharma, P.J. Pellechia, F.-S. Ke, X.-D. Zhou, J. Electrochem. Soc. 160 (2013) F953-F957.

[34] Q. Wang, H. Dong, H. Yu, H. Yu, J. Power Sources 279 (2015) 1-5.

[35] U. Pasaogullari, C.-Y. Wang, Electrochim. Acta 49 (2004) 4359-4369.

[36] J.J. Borodziński, A. Lasia, Int. J. Hydrogen Energy 18 (1993) 985-994.

[37] Z. Qi, A. Kaufman, J. Power Sources 109 (2002) 38-46.

[38] H.-R. Jhong, F.R. Brushett, L. Yin, D.M. Stevenson, P.J.A. Kenis, J. Electrochem. Soc. 159 (2012) B292-B298.

[39] A.J. Martin, G.O. Larrazabal, J. Perez-Ramirez, Green Chemistry (2015). 


\section{Tables}

Table 1. Physical properties and composition of gas diffusion electrodes

\begin{tabular}{c|c|c|c|c|c|c}
\hline $\begin{array}{c}\text { Sample composition } \\
\text { (Carbon / MPL PTFE / } \\
\text { CFS thickness-wet } \\
\text { proofing) }\end{array}$ & \multicolumn{3}{|c|}{ MPL } & \multicolumn{3}{c}{ CFS } \\
\cline { 2 - 7 } & $\begin{array}{c}\text { Carbon } \\
\text { Loading } \\
\left(\mathbf{m g ~ c m}^{-2}\right)\end{array}$ & $\begin{array}{c}\text { PTFE } \\
\text { Amount } \\
(\mathbf{w t \% )}\end{array}$ & $\begin{array}{c}\text { Thickness } \\
(\boldsymbol{\mu m})\end{array}$ & Type & $\begin{array}{c}\text { Thickness } \\
(\boldsymbol{\mu m})\end{array}$ & $\begin{array}{c}\text { Wet } \\
\text { proofing } \\
(\boldsymbol{\%})\end{array}$ \\
\hline $\mathbf{1 / 2 0 \% / 6 0 - 1 0 \%}$ & 1.0 & 20 & 15 & Toray-60 & 190 & 10 \\
$\mathbf{1 / 2 0 \% / 9 0 - 1 0 \%}$ & 1.0 & 20 & 15 & Toray-90 & 280 & 10 \\
$\mathbf{1 / 2 0 \% / 1 2 0 - 1 0 \%}$ & 1.0 & 20 & 15 & Toray-120 & 370 & 10 \\
$\mathbf{1 / 2 0 \% / 6 0 - 3 0 \%}$ & 1.0 & 20 & 15 & Toray-60 & 190 & 30 \\
$\mathbf{1 / 2 0 \% / 6 0 - 5 0 \%}$ & 1.0 & 20 & 15 & Toray-60 & 190 & 50 \\
Sigracet 35BC & unknown $^{1}$ & unknown $^{1}$ & 80 & Sigracet 35 BC & 325 & 5 \\
\hline
\end{tabular}

1. The commercial provider did not provide this information. 
Table 2. Gas permeation data for GDEs with different level of wet proofing and different thickness of the CFSs.

\begin{tabular}{c|c}
\hline $\begin{array}{c}\text { Sample composition } \\
\text { (Carbon / MPL PTFE / CFS } \\
\text { thickness-wet proofing) }\end{array}$ & $\begin{array}{c}\text { Flow rate of } \\
\text { permeant gas } \\
{\text { (ml } \text { min }^{-1} \text { ) }}^{-1}\end{array}$ \\
\hline $\mathbf{1 / 2 0 \% / 6 0 - 1 0 \%}$ & $72.42 \pm 0.72$ \\
$\mathbf{1 / 2 0 \% / 9 0 - 1 0 \%}$ & $70.19 \pm 0.70$ \\
$\mathbf{1 / 2 0 \% / 1 2 0 - 1 0 \%}$ & $69.25 \pm 0.69$ \\
$\mathbf{1 / 2 0 \% / 6 0 - 3 0 \%}$ & $71.13 \pm 0.71$ \\
$\mathbf{1 / 2 0 \% / 6 0 - 5 0 \%}$ & $70.72 \pm 0.70$ \\
Sigracet 35BC & $52.15 \pm 0.52$ \\
\hline
\end{tabular}




\section{Captions to Figures}

Figure 1. Fabrication procedure for GDE

Figure 2. Micro-CT images (top view) and SEM images (cross-sectional view) of Ag-sprayed on Toray paper with MPL (a) and (b); and without MPL (c) and (d). (e) Partial current density for CO with two GDEs: Ag-sprayed on Toray paper with and without MPLs.

Figure 3. Partial current density for $\mathrm{CO}$ and $\mathrm{H}_{2}$ as a function of different potentials for GDEs comprised of MPLs with different amounts of PTFE wt\%: (a) and (b) 4.5, 7, 10, 15 and $20 \mathrm{wt} \%$. (c) and (d) 20, 30, 40 and $50 \mathrm{wt} \%$. (e) Impedance spectra for GDEs at a cell potential of -2.0 V. (f) Partial current density for $\mathrm{CO}$ at a cathode potential of $-2.2 \mathrm{~V}$ vs. $\mathrm{Ag} / \mathrm{AgCl}$ as a function of GDEs with different PTFE amounts of MPL. $\mathrm{N}=3$ for each data plot.

Figure 4. Partial current density for $\mathrm{CO}$ as a function of different potentials for GDEs with different wet proof level of CFSs (10 - 50\%) with two different feeds of (a) $100 \% \mathrm{CO}_{2}$ and (b) mixture of $50 \% \mathrm{CO}_{2} /$ $50 \% \mathrm{~N}_{2}$. (c) Impedance spectra for GDEs with different wet proof level of CFSs at a cell potential of -2.0 V. N=3 for each data plot. Figure 5. Partial current density for $\mathrm{CO}$ as a function of time when using GDEs with $10 \%$ and $50 \%$ wet proof level of CFSs over a total of 4 hours.

Figure 5. Partial current density for $\mathrm{CO}$ as a function of time when using GDEs with $10 \%$ and $50 \%$ wet proof level of CFSs over a total of 4 hours.

Figure 6. Partial current density for $\mathrm{CO}$ as a function of different potentials for GDEs with different thickness of CFSs (including Sigracet 35BC) with two different feeds of (a) $100 \% \mathrm{CO}_{2}$ and (b) mixture of $50 \% \mathrm{CO}_{2} / 50 \% \mathrm{~N}_{2}$. $\mathrm{N}=3$ for each data plot. 


\section{Figures}

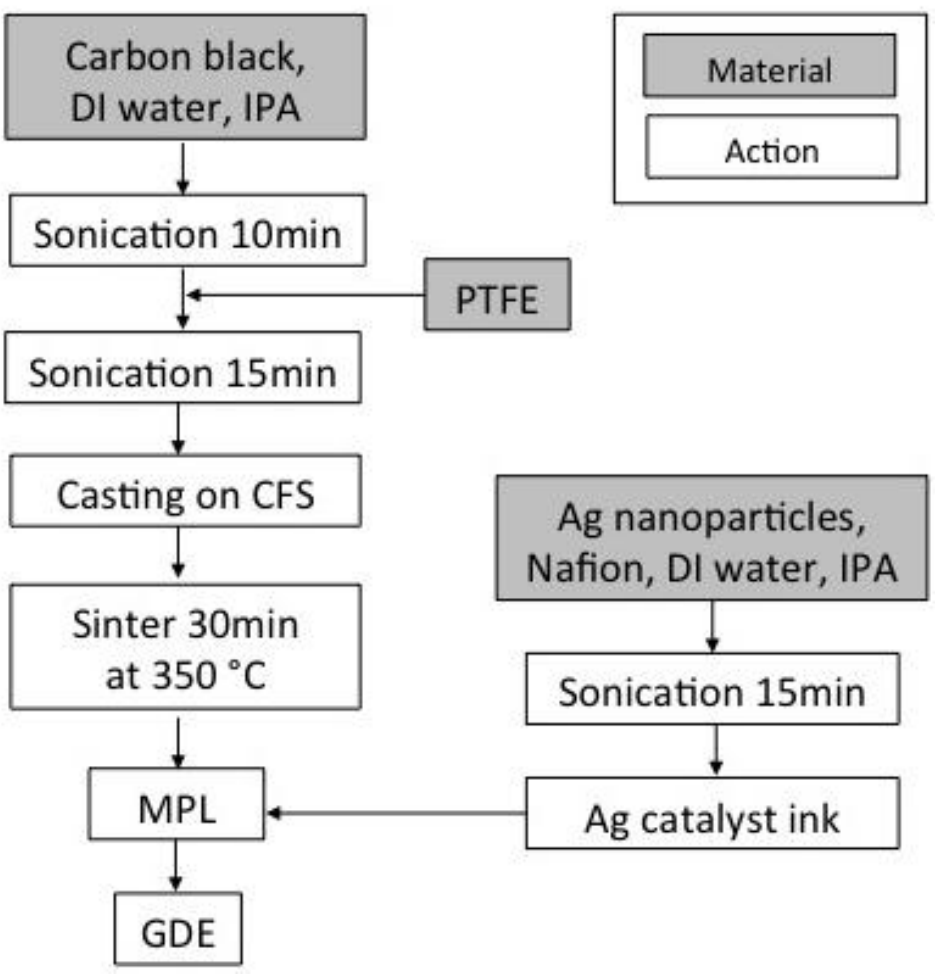

Figure 1. Fabrication procedure for GDE 


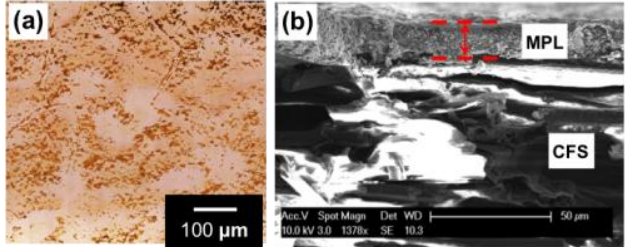

With MPL (20 wt\%)

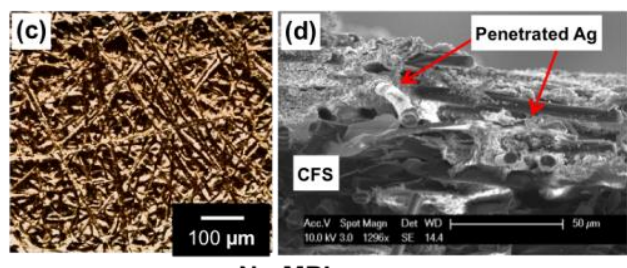

No MPL

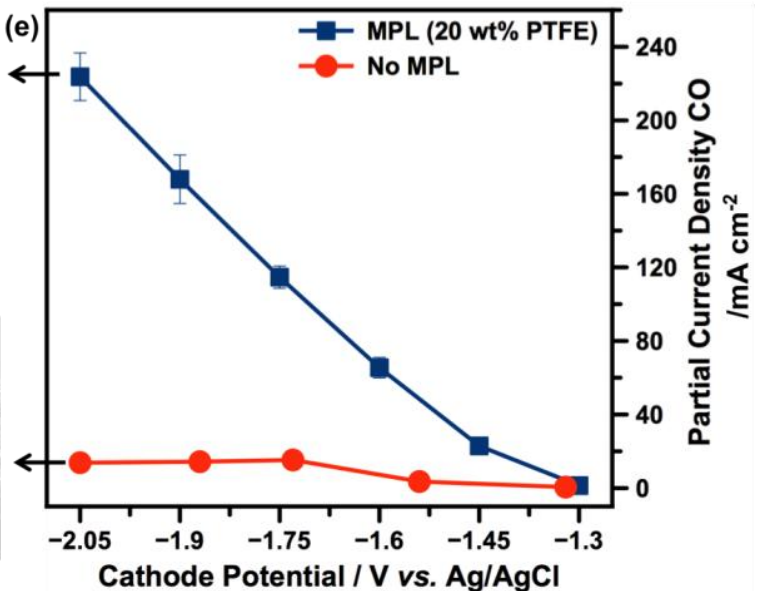

Cathode Potential / V vs. Ag/AgCl

Figure 2. Micro-CT images (top view) and SEM images (cross-sectional view) of Ag-sprayed on Toray paper with MPL (a) and (b); and without MPL (c) and (d). (e) Partial current density for CO with two GDEs: Ag-sprayed on Toray paper with and without MPLs. 

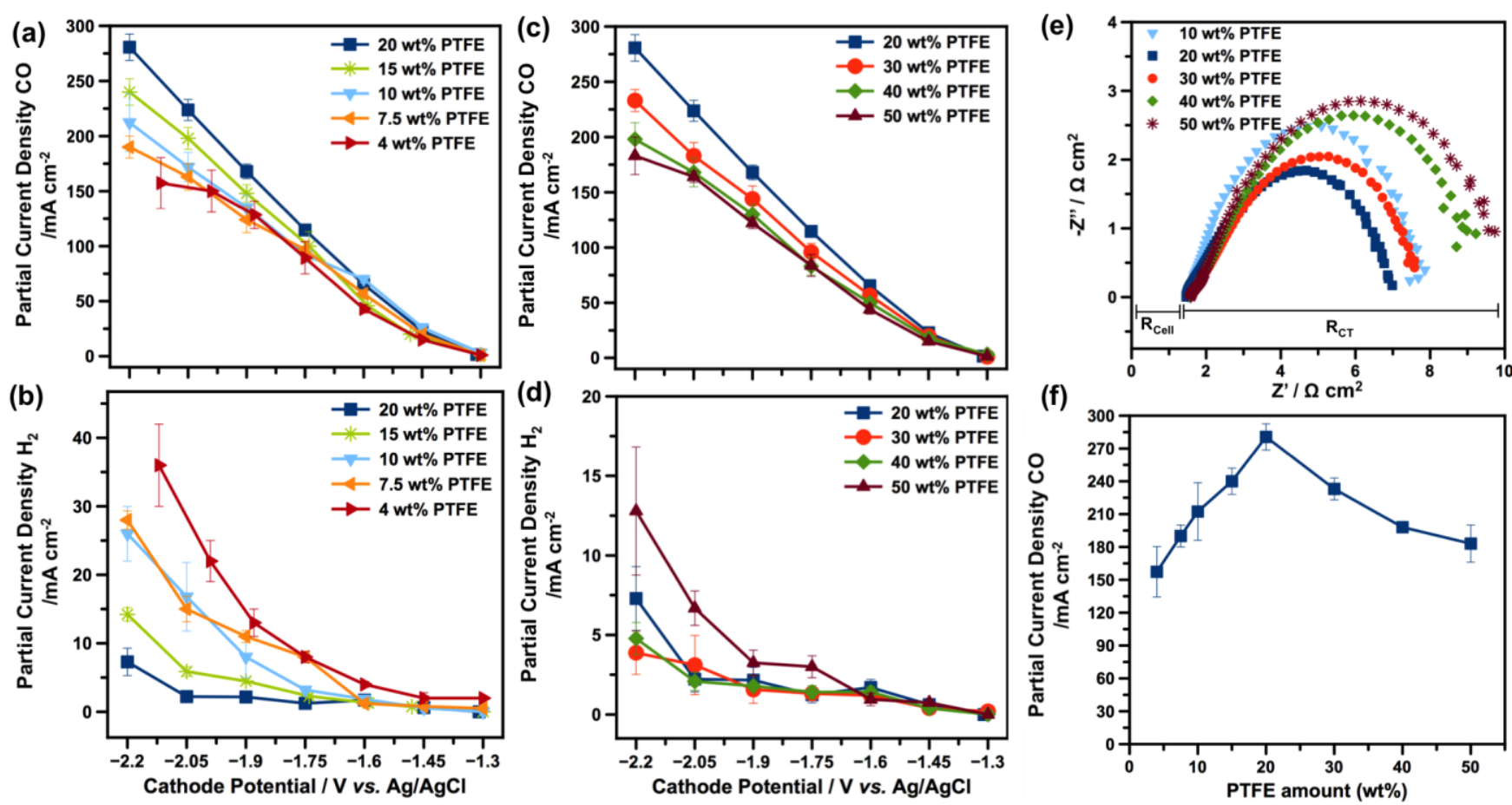

Figure 3. Partial current density for $\mathrm{CO}$ and $\mathrm{H}_{2}$ as a function of different potentials for GDEs comprised of MPLs with different amounts of PTFE wt\%: (a) and (b) 4.5, 7, 10, 15 and $20 \mathrm{wt} \%$. (c) and (d) 20, 30, 40 and $50 \mathrm{wt} \%$. (e) Impedance spectra for GDEs at a cell potential of -2.0 V. (f) Partial current density for $\mathrm{CO}$ at a cathode potential of $-2.2 \mathrm{~V}$ vs. $\mathrm{Ag} / \mathrm{AgCl}$ as a function of GDEs with different PTFE amounts of MPL. N=3 for each data plot. 

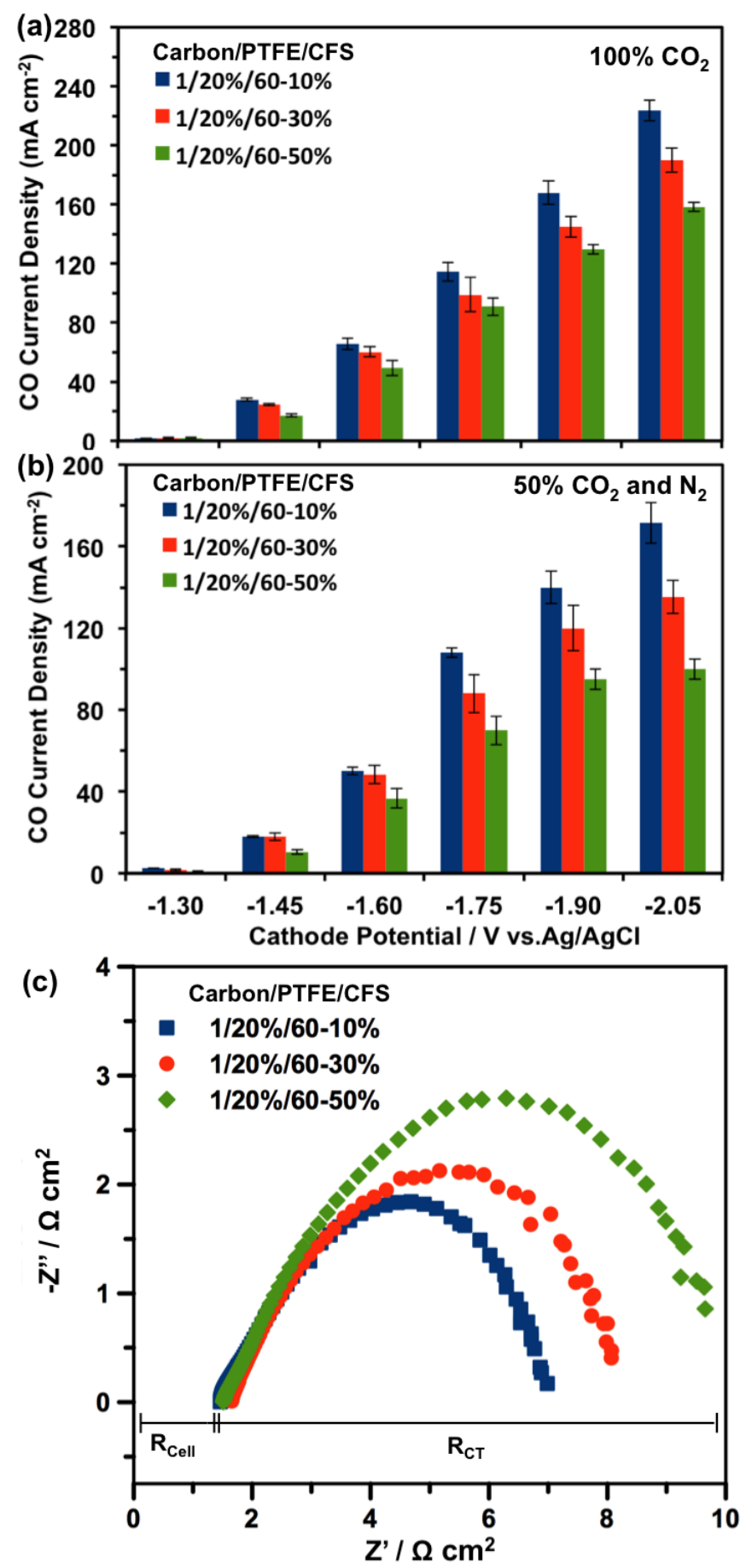

Figure 4. Partial current density for $\mathrm{CO}$ as a function of different potentials for GDEs with different wet proof level of CFSs (10 - 50\%) with two different feeds of (a) $100 \% \mathrm{CO}_{2}$ and (b) mixture of $50 \% \mathrm{CO}_{2} /$ $50 \% \mathrm{~N}_{2}$. (c) Impedance spectra for GDEs with different wet proof level of CFSs at a cell potential of $-2.0 \mathrm{~V} . \mathrm{N}=3$ for each data plot. 


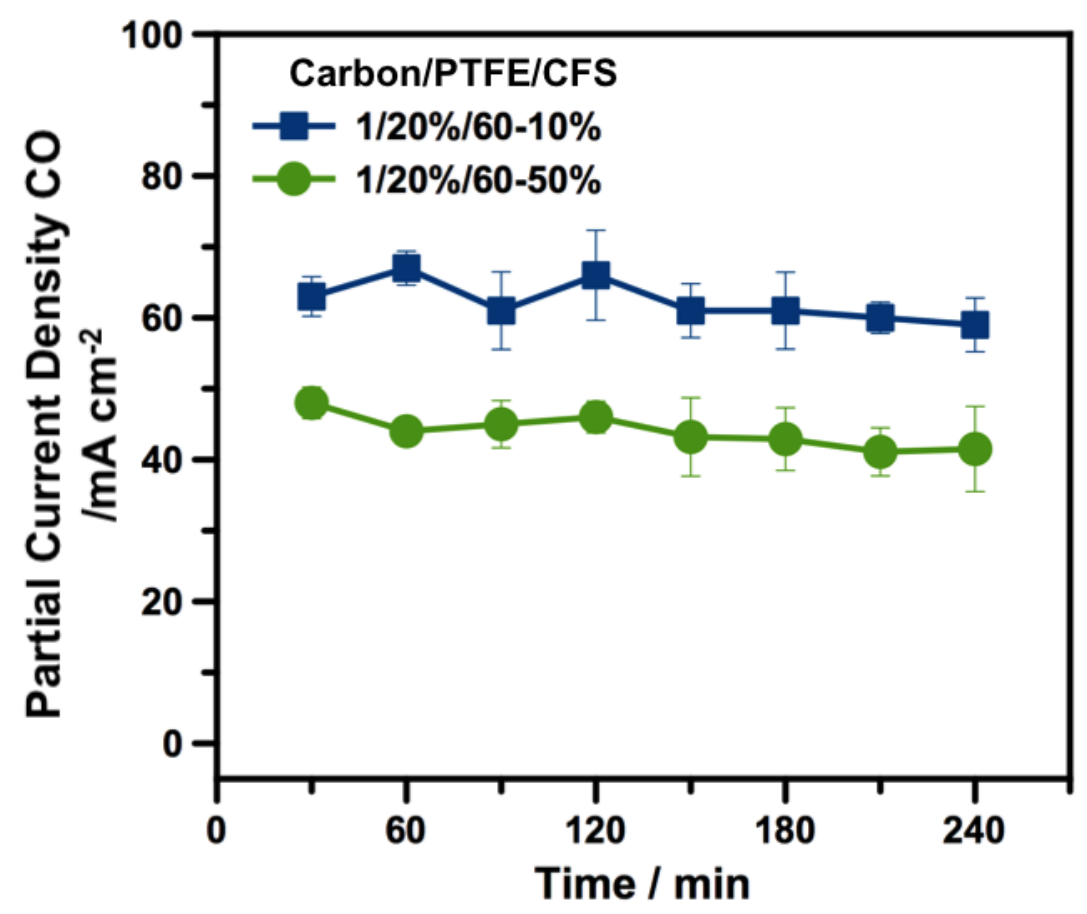

Figure 5. Partial current density for $\mathrm{CO}$ as a function of time when using GDEs with $10 \%$ and $50 \%$ wet proof level of CFSs over a total of 4 hours. 


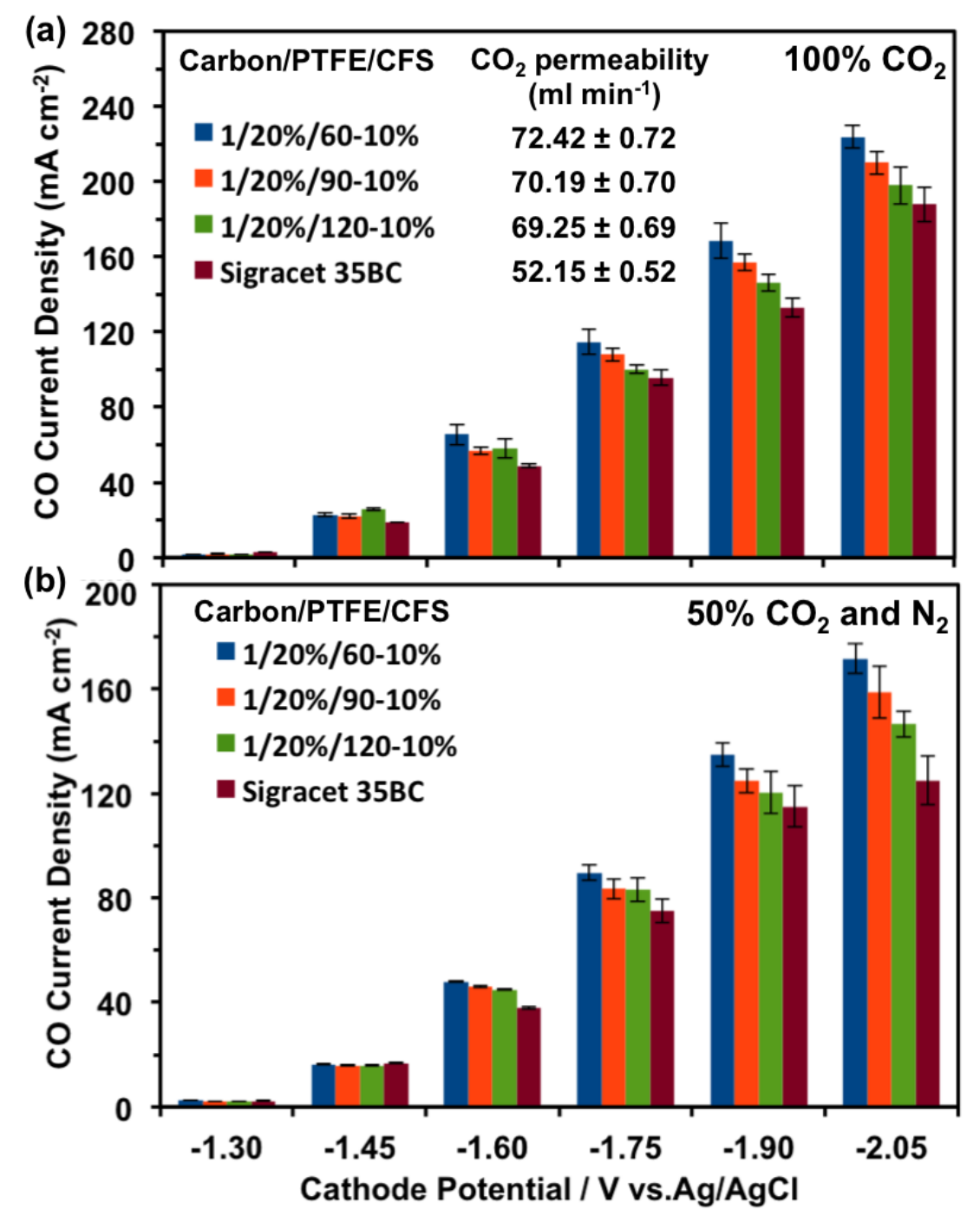

Figure 6. Partial current density for $\mathrm{CO}$ as a function of different potentials for GDEs with different thickness of CFSs (including Sigracet 35BC) with two different feeds of (a) $100 \% \mathrm{CO}_{2}$ and (b) mixture of $50 \% \mathrm{CO}_{2} / 50 \% \mathrm{~N}_{2}$. $\mathrm{N}=3$ for each data plot. 